Case Report

\section{Patellar fractures in children}

\author{
Mohammed Shabeer ${ }^{1 *}$, Nasir Muzaffar ${ }^{2}$ and Sameh Abdalla ${ }^{2}$ \\ 1Specialist Orthopaedic Surgeon, Al Wakra Hospital, Hamad Medical Corporation, Qatar \\ ${ }^{2}$ Department of Orthopaedics, Al Wakra Hospital, Hamad Medical Corporation, Qatar
}

\section{Summary}

We describe a rare case of patellar fracture in a seven year old girl. The case was reviewed for various aspects such as clinical diagnosis, imaging tests and most suitable treatment.

\section{More Information}

*Address for Correspondence: Dr. Mohammed Shabeer, Specialist Orthopaedic Surgeon, Al Wakra Hospital, Hamad Medical Corporation, Qatar, Tel: 00974 33107713; Fax: 00974 82284; Email: drshabeer2010@gmail.com

Submitted: 28 October 2019

Approved: 18 November 2019

Published: 19 November 2019

How to cite this article: Shabeer M, Muzaffar $\mathrm{N}$, Abdalla S. Patellar fractures in children. Arch Case Rep. 2019; 3: 040-042.

DOI: dx.doi.org/10.29328/journal.acr.1001021

Copyright: (c) 2019 Shabeer M, et al. This is an open access article distributed under the Creative Commons Attribution License, which permits unrestricted use, distribution, and reproduction in any medium, provided the original work is properly cited.

Pediatric patellar fractures are relatively uncommon. However, when reported, they involve patients younger than 16 years [1]. The peak incidence is between 8-12 years of age [2]. The reason for this is the relative flexibility of the patella in childhood which is less affected by impact and tension forces during quadriceps contraction [3]. The mechanism of such fractures is either due to direct trauma and/or excessive contraction of the extensor mechanism. Houghton and Ackroyd [4], elucidated an avulsion-type fracture of the lower end of the patella; in such fractures a significant chunk of cartilage is avulsed from the patella affixed to a discreet bone fragment. Such fractures may not be commonly diagnosed, especially if there is a large hemarthrosis or if X-ray studies aren't clear about the fracture line [4,5]. In such cases, MRI of the knee is the diagnostic modality of choice [6,7], in the detection of this condition in order to avoid later damage to knee extension or the formation of megapatellas with irregular joint surface [810].

\section{Case Report}

A seven year old Ghanaian girl was running at school and she collided with another girl and her right knee hit a concrete pillar. When she presented to emergency department she had complaints of pain and swelling right knee and inability to bear weight on right lower limb. On examination, there was moderate swelling and tenderness over right patella. The patient could not perform an active extension of the knee. Xrays revealed a patellar fracture.

Patient was admitted to the hospital and was given analgesics and knee immobiliser. She was treated by Open reduction and Internal Fixation using $\mathrm{K}$ wires and Tension Band Wiring in the following day. A cylinder slab was advised for 3 weeks post operatively. Immobilisation with plaster was discontinued after 3weeks and X-ray showed fracture was uniting well. She was referred to physiotherapy and was advised knee mobilisation exercises and partial weight bearing.

\section{Radiograph before surgery (Figure 1A,B)}

She was followed up regularly and at 6 weeks clinically there was no tenderness at the fracture site.

Her knee ROM was full with full active flexion and extension and she was bearing full weight. Check X-rays showed complete union of fracture at 6 weeks.

At the last follow up at 6 months, the child was asymptomatic and was advised implant removal.
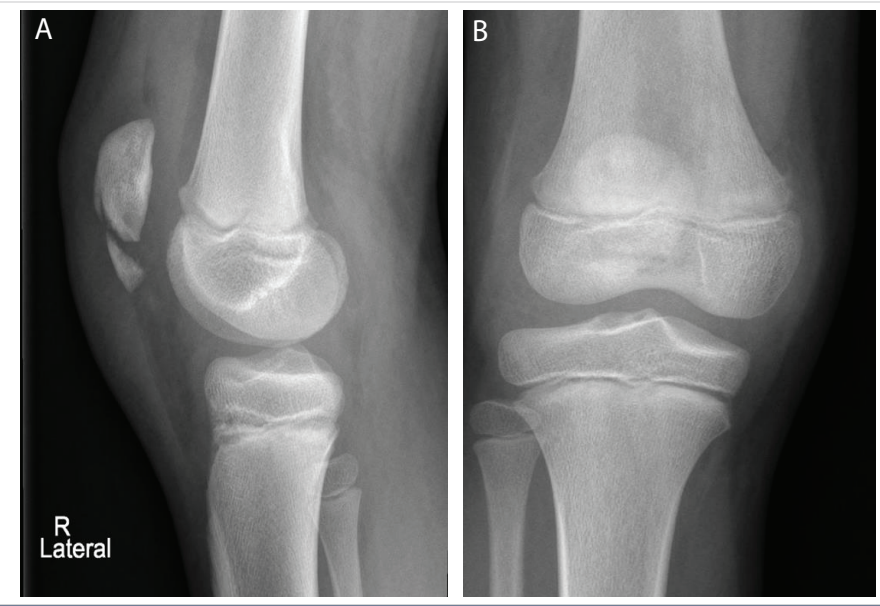

Figure 1AB: Radiograph before surgery. 
Radiograph after six weeks (Figure 2A,B)

Radiograph After 6 Months (Figure 3A,B)

\section{Discussion}

The girl in our case report had an age less than the usually reported age group of patellar fractures in children which is 8-12 years [1]. This may be due to a combination of direct and indirect trauma that is the peculiar mechanism of injury which occurred in our patient.

The predominant quandary regarding pediatric patellar fractures is the diagnosis. Often, congenital anomalies may mimic fractures [11,12]. Another issue in such cases is difficulty in gauging the size of the fracture fragments, more so in sleeve-type fractures due to the cartilaginous nature of the patella [13]. Belman and Neviaser [1] reported that missed or delayed diagnoses are common for patellar fractures in children. Sleeve-type patellar fractures often occur in children who take part in activities requiring knee extension force with quadriceps contraction against resistance, with injury occurring on the supportive leg. Hence, this form of injury is unlike those due to direct knee trauma [4]. Grogan, et al. [14] gave his classification of pediatric patellar fractures based on their anatomic location. The proximal avulsion fracture, which
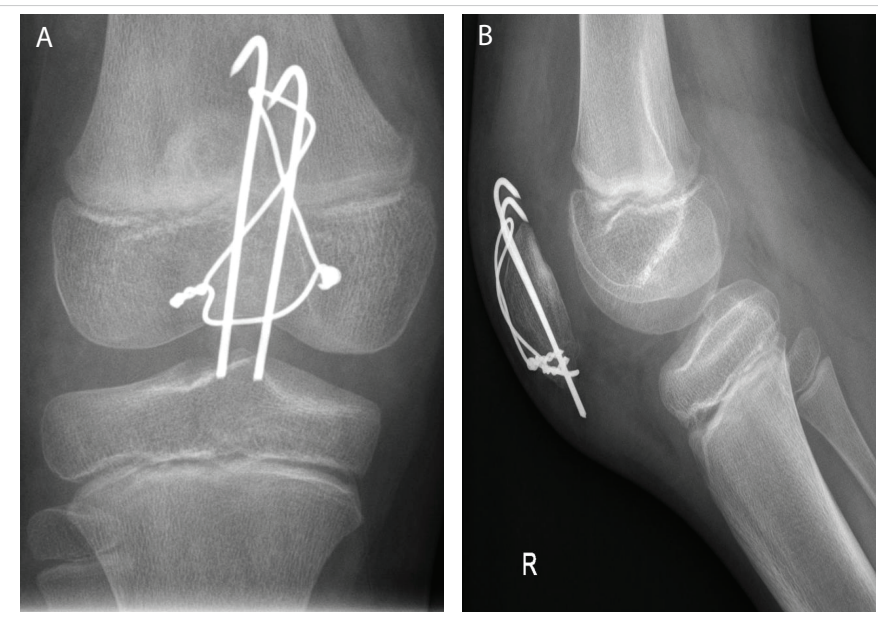

Figure 2AB: Radiograph after six weeks.
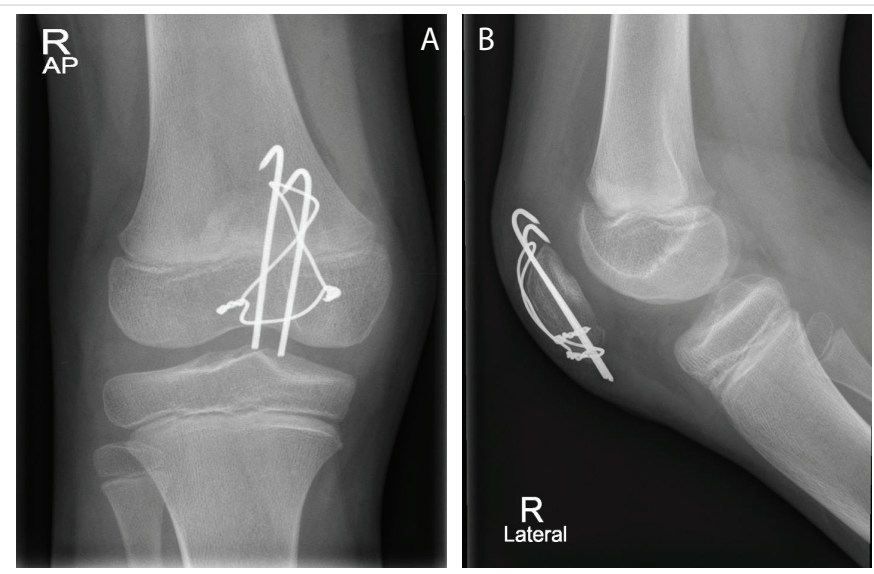

Figure 3AB: Radiograph after 6 months. is the commonest, involves the patellar upper pole while as the distal end avulsion is commonly traumatic, just like our case. Medial avulsion injury can be seen after a lateral patellar dislocation. The avulsion of the superolateral corner of the patella may be mistaken for a bipartite patella or may be stress induced due to repeated traction of the vastus lateralis muscle [12]. A similar stress induced injury is the Sinding-LarsenJohansson disease, due to repeated stress of the distal patellar end causing an incomplete avulsion of the patellar ligament fibers and subsequent necrosis and calcification [15].

To be aware of the possibility of such an injury, a good history along with characteristic radiological features should lead to the diagnosis. The avulsed patellar fragment invariably includes a sizable sleeve of cartilage; it is imperative that this fragment must be accurately reduced to re-establish the articular surface of patella [4].

The treatment of paediatric patellar fractures with splints in lower limb extension can result in a reconstruction of the extensor apparatus, but a patellar deformity can remain (megapatella) with motion restraint, especially in extension $[16,17]$. Extensor mechanism reconstruction surgery with absorbable sutures has not shown good results $[4,17,18]$. The most ideal treatment method seems to be the rigid internal fixation of the fracture with emphasis on anatomical reduction and the realignment of the joint cartilage [4]. When bone fragments are small, internal fixation must be performed by a tension band $[4,19]$. The stability of internal fixation can be augmented by suturing medial and lateral retinacula which is very important. With rigid fixation, active flexion and extension exercises of the knee are initiated as early as possible as soon as the wound has healed and a normal range of movements of knee was achieved within a few weeks as we observed in our case.

Tsubosaka et al. [18] has reported a case of fracture patella in a 12 year old boy following a skateboard injury. As tension band wiring was unsuccessful it was treated with trans osseous tunnelling and suturing with ethibond 5 and cerclage wiring of patella.

Ndeleva et al. [20] has reported a case of transverse fracture patella in a 10 year old boy 2 months after a fall. He was treated with tension band wiring.

Johan Kirkegaard, et al. [21] has reported a case of fracture patella in a 11 year old boy which was missed initially and later diagnosed after 6 weeks with MRI scan. He was treated with open reduction and fixation of patella using cerclage and fiber wire sutures.

\section{Conclusion}

Although fractures of the patella in children are uncommon, we should think of it as one of differential diagnoses in cases of acute knee injuries especially when the injury was caused 
by excessive force such as jumping or sports injuries. The diagnosis can often be missed in fractures with a very small avulsed bony fragment. We suggest MRI scan in doubtful cases for early diagnosis and early surgical intervention and internal fixation with mobilization can achieve excellent results for displaced fractures of the patella.

\section{References}

1. Belman DAJ, Neviaser RJ. Transverse fracture of the patella in a child J Trauma. 1973; 13: 917-918.

2. Beaty $\mathrm{JH}$, Kumar A. Current concepts review. Fractures about the knee in children. J Bone Joint Surg Am. 1994; 76: 1870-1880.

3. Beaty JH, Roberts JM. Fraturas e luxações do joelho In: Rockwood CA Jr, Wilkins KE, King RE. Fraturas em crianças. Tradução de Vilma Ribeiro de Souza Varga, et al. $3^{\text {a }}$ ed. São Paulo: Manole; 1993; 1196-1207.

4. Houghton GR, Ackroyd CE. Sleeve fractures of the patella in children. $J$ Bone Joint Surg Br. 1979; 61: 165-168.

5. Ray JM, Hendrix T. Incidence, mechanism of injury and treatment of fractures of the patella in children. J Trauma. 1992; 32: 457-464. PubMed: https://www.ncbi.nlm.nih.gov/pubmed/1569620

6. Soundry M, Lanir A, Angel D, Roffman M, Kaplan N, et al. Anatomy ofnormal knee as seen by magnetic resonance imaging. J Bone Joint Surg Br. 1986; 68: 117-120.

PubMed: https://www.ncbi.nlm.nih.gov/pubmed/3941127

7. Wessel LM, Scholz S, Rüsch M, Kopke J, Loff S, et al. Hemarthrosis after trauma to the pediatric knee joint: what is the value of magnetic resonance imaging in the diagnostic algorithm? J Pediatr Orthop. 2001; 21: 338-342.

PubMed: https://www.ncbi.nlm.nih.gov/pubmed/11371817

8. Shands PA, McQueen DA. Demontration of avulsion fracture of the inferior pole of the patella by magnetic resonance imaging. $J$ Bone Joint Surg Am. 1995; 77: 1721-1723.

PubMed: https://www.ncbi.nlm.nih.gov/pubmed/7593083

9. Dafner RH, Riemer BL, Lupetin AR, Dash N. Magnetic resonance imaging in acute tendon ruptures. Skeletal Radiol. 1986; 15: 619-621. PubMed: https://www.ncbi.nlm.nih.gov/pubmed/3810183

10. Mandelbalbaum BR, Finerman GA, Reicher MA, Hartzman S, Bassett LW, et al. Magnetic resonance imaging as a tool for evaluation of traumatic knee injuries. Anatomical and pathoanatomical correlations.
Am J Sports Med. 1986; 14: 361-370.

PubMed: https://www.ncbi.nlm.nih.gov/pubmed/3535549

11. Andersen PT. Congenital deformities of the knee joint in dislocation of the patella and achondroplasia. Acta Orthop Scand. 1958; 28: 27-50. PubMed: https://www.ncbi.nlm.nih.gov/pubmed/13605709

12. Peterson L, Stener B. Distal disinsertion of the patellar ligament combined with avulsion fractures at the medial and lateral margins of the patella. A case report and an experimental study. Acta Orthop Scand. 1976; 47: 680-685.

PubMed: https://www.ncbi.nlm.nih.gov/pubmed/1015265

13. Morrissy RT, Weinstein SL. Fractures and dislocations abaut the knee. In: Lovell WW, Winter RB.Lovell \& Winter's Pediatric Orthopaedics. 5th ed. New York: Williams \& Wilkins; 2001: 1389-1396.

14. Grogan DP, Carey TP, Leffers D, Ogden JA. Avulsion fractures of the patella. J Pediatr Orthop. 1990; 10: 721-730.

PubMed: https://www.ncbi.nlm.nih.gov/pubmed/2250056

15. Gardiner JS, Mclnerney VK, Avella DG, Valdez NA. Pediatric update \# 13. Injuries to the inferior pole of the patella in children. Orthop Rev. 1990; 19: 643-649.

PubMed: https://www.ncbi.nlm.nih.gov/pubmed/2381739

16. Bensahel H, Sprung R. Les fractures de la rotule de l'enfant. J Chir (Paris). 1970; 99: 45-54

17. Wilson JN, Watson-Jones R. Fraturas. Traumatismos das articulações. Tradução de José Henrique da Matta Machado et al.. $5^{\text {a }}$ ed. Rio de Janeiro: Guanabara; 1978. Beddow FH, Corkery PH, Shatwell GL. Avulsion of the ligamenttum patellae from the lower pole of the patella. J R Coll Surg Edinb. 1963; 9: 66-69.

PubMed: https://www.ncbi.nlm.nih.gov/pubmed/14067959

18. Tsubosaka M, Makino T, Kishimoto S, Yamaura K. A Case Report of Sleeve Fracture of Patella in a Child. J Orthop Case Rep. 2016; 6: 24-27. PubMed: https://www.ncbi.nlm.nih.gov/pmc/articles/PMC5404155/

19. Wessel LM, Scholz S, Rüsch M. Characteristic pattern and management of intra-articular knee lesions in different pediatric age groups. J Pediatr Orthop. 2001; 21: 14-19.

PubMed: https://www.ncbi.nlm.nih.gov/pubmed/11176347

20. Ndeleva BM, Lakati CK, Lutomia ML, Mak'Anyengo SO. Transverse Patella Fracture in a Ten year old boy: Case Report; EAOJ. 2013; 7: 64-67.

21. Kirkegaard J, Bieder M, Mallet SK, Fabrin J. Late MRI detected patellar sleeve fracture: A case report and review of the literature. J Case Rep Images Orthop Rheum. 2017; 2: 1-6. 